DE DE GRUYTER

OPEN

บ

DOI: 10.2478/topling-2014-0005

\title{
Interviewing in the Medical Context: Questions, Answers, Assessments - An Interdisciplinary Approach
}

\author{
Monika Gyuró \\ Pécs University, Hungary
}

\begin{abstract}
There has been a large amount of research done on doctor-patient encounters analysing the linguistic and discursive peculiarities occurring in these interactions. Though many relevant features of medical interviewing are well-known to the scientific public, there are still areas for further investigation. One of these areas is the sequential organisation of the dialogues between patients and doctors.

This paper aims to show the pragmatic means that contribute to the efficacy of doctorpatient talk. As a method, the contribution applies the Sociocognitive Approach to Critical Discourse Analysis. The sequential organisation of therapeutic dialogues involves the use of particular speech acts (questions, answers, assessments) that are characteristic of the comforting and confirming procedures of the therapist. The paper intends to analyse the parts of the therapeutic interview (initiation, exploration and termination) to show patientcentredness in interviewing and the sequential organisation of empathy and confirmation with the help of an interview transcript between a doctor and patient after a renal transplant.
\end{abstract}

\section{Keywords}

Medical interviewing, therapeutic dialogue, Sociocognitive Approach, sequential organisation, speech acts.

\section{Introduction}

The interaction between healers and patients has been a focus of interest for as long as people have been sick, which is to say, as long as mankind has existed. In recent times healthcare systems have been changing all over the world, with the appearance of new healthcare specialisms and the expansion of the number of healthcare professionals. In some countries the changes are attributed to a shift to the institutionalisation of medical consumerism (USA, Great Britain), in other countries similar processes can be seen by the spreading of individualism and the democratisation of the doctor-patient relationship (Buda, 1994) resulting in patient-centred communication with clients. The rise of the challenging linguistic disciplines from the $1960 \mathrm{~s}$ stimulated intensive research on medical encounters to show power inequalities, communicative strategies and the linguistic markers of personal relationships in this context. In particular, Foucault (1969), Sacks, Schegloff, and Jefferson (1974), Todd (1983), Mishler (1984), ten Have (2002), as conversational and discourse analysts highlighted the mutual connections between language and behaviour during consultation.

In relation to the study carried out, the present paper seeks to show how the patient-centered approach to therapeutic interviews demonstrates the way experts let patients reveal their thoughts related to the problems presented in the interview. Patientcentred communication means that the focus of interaction is on the client. In this model the helper is encouraged to communicate empathy, congruence and positive regard towards the patient. Patient- 
centered communication is an organising power in the psychological and pragmatic aspects of therapeutic discourse.

In addition to this, the paper examines the sequential organisation of medical dialogues comprising typical speech acts: questions, answers and assessments (reactives). The pragmatic analysis of the speech acts will show the behaviour underlying the participants' intentions in a given situation. Many papers have dealt with the power inequalities of the participants in a medical context (Parsons, 1951; Foucault, 1979; Fisher and Todd, 1983; Mishler, 1984; Waitzkin, 1989; Schiffrin, 2008). The present paper emphasises that the professional not only plays a dominant role in the conversation but provides supportive information towards the patient as well. Therefore, it should be recognised that less attention has been devoted to revealing certain linguistic peculiarities of supportive communication between professionals and clients in therapy than is merited. The present paper intends to overcome these shortcomings by demonstrating how particular speech acts are used for the feedback of the speaker to show confirmation, support and understanding towards the other party within patientcentred therapeutic communication. The investigation of the association between the reactives of doctors and patients has not been reported previously. This study aims to build on existing research by characterising the assessment types of the doctor showing empathy and the reactives of both parties in the doctor-patient therapeutic consultation to present the different attitudes of the participants.

\section{Interdisciplinary aspects of clinical discourse analysis}

Scholars from various fields of science regard clinical encounters as communication events and also consider important a commitment to careful description and analysis of linguistic data and a concern to explore human behaviour in the clinical context. The beginning of the inquiry into clinical interaction originates from a fundamental project, The Natural History of the Interview (NHI). The NHI (McQuown, 1971) was an interdisciplinary project involving psychiatrists (Frieda Fromm, Henry W. Brosin), anthropologist (Gregory Bateson), linguists (Charles F. Hockett and Norman A. Mc Quown) studying speech and motion in recorded interviews. Following the early projects, several significant ventures into clinical practice (Labov and Fanshel, 1977) occurred. Nowadays, researchers use methods that range from the analysis of institutional talk (Drew and Heritage, 1992) to interaction analysis used to show dominance in human relationships (Foucault, 1969; Mishler, 1986).

The purpose of the interdisciplinary work between linguists and clinicians is to invigorate collaborations between communication-based experts and medical practitioners. Researchers working collaboratively are constructing a "basic science of listening-and-talking" (Percy, 1987, p.159).

Discourse-based investigations seem to be fruitful approaches to clinical interactions. Discourse and conversation analysts focus on the naturally occurring talk and the use of recording of language data to obtain details in interaction that would be impossible any other way. The results of the research may be shared with other medical professionals in order to enhance understanding in a clinical situation that may lead to better therapy.

The explanation for the importance of linguistic research in the clinical field is that it combines research work, linguistics and medicine. On the one hand, clinicians can learn more about patients' attitudes, intentions and behaviour. On the other hand, clinical encounters are excellent opportunities for discourse analysts to provide a detailed description of a life event.

\section{Method}

According to Wodak and Meyer (2008), Critical Discourse Analysis regards language as a social practice and also considers the context of language use to be required. Critical Discourse Analysis understands discourses as forms of language in organising social life.

Power seems to be a central concept for Critical Discourse Analysis researchers; thus, Critical Discourse Analysis focuses on the ways discourse produces social inequalities and domination. In other words, Wodak $(2008, \quad$ p.10) suggests that "Critical Discourse Analysis aims to investigate critically social inequality as it is expressed, constituted, legitimized, and so on, by language use (or in discourse)." Critical Discourse Analysis supports the need for interdisciplinary work to show how language works in organising institutions and in 
exercising power, in different fields of society.

The Sociocognitive Approach is on the sociopsychological side of Critical Discourse Analysis and serves a sound basis for further study (ibid., p.26). The Sociocognitive Approach draws on the social representation theory (Moscovici, 2000). Moscovici refers to the notion above as a bulk of opinions, attitudes and evaluations that originate from everyday life and are maintained by communication. Thus, social representations form an essential part of the individual's social identity. These representations such as knowledge, attitudes and ideologies direct the pragmatic part of the discourse. Therefore, the Sociocognitive Approach uses the following local meanings as linguistic markers in the study: implicit meanings such as presuppositions and implicatures, speech acts, turn-takings, and word order (Wodak and Meyer, 2008). The present paper investigates speech acts and the sequential organisation of a doctor-patient dialogue to show how clinicians' social position is used for expressing empathy in the healthcare context.

\section{Medical interview as a form of institutional discourse}

Medical interviews are a part of institutional discourse characterised by the members' roles in the speech events in which they participate. For the purpose of this study, the following definition can be adopted by Thornborrow (2002, p.5):

"[...] institutional discourse can perhaps be best described as a form of interaction in which the relationship between the participants' current institutional role and their current discursive role emerges as a local phenomenon which shapes the organisation and trajectory of the talk."

All types of institutional discourse share common features such as dialogical arrangement of talk, asymmetrical power distribution, specially organised talk and technical vocabulary which makes the discourse relevant to the work activities in which people are engaged (Shuy, 1983).

The healthcare interview plays an important role in institutional or clinical practice, because information-provision, datagathering, discussing results, monitoring the outcomes of treatment, and building relationships all depend on interviewing.

Examining healthcare interviews, similarities and differences in interpersonal communication can be found. Both types of communication form involve two persons interacting with each other verbally and nonverbally. Nevertheless, interviews bear specific features that differentiate them from other types of interpersonal communication. Interviews are intentional, because participants always keep the conversation focused on certain topics. Secondly, the form of the interviews is realised in questions and answers. Thirdly, focusing on healthcare interviews only, the goal of the interviews can be twofold: sharing information and providing therapy (Northouse, 1998).

Information-sharing interviews emphasise content, while therapeutic interviews focus on the relational dimensions in interaction. Not all interviews appear to be clearly identifiable specimens of the two mentioned types, and some of them seem to be mixed in features, e.g. in advice giving. Therapeutic interviews identify personal issues; therefore, patients are able to express their feelings, develop problem-solving strategies and improve their own mental states of health. In this respect, therapeutic interviews demonstrate similarities with biopsychosocial interviewing techniques, where the patient is at the centre of examination. Conducting therapeutic interviews can be accomplished in two major ways: in directive and non-directive approaches. In directive interviews, the interviewer controls the patient, prescribes therapy and tries to solve problems, while in non-directive interviews the interviewee has most of the role the professional has in the directive approach apart from factual decision-making. Both approaches have advantages and disadvantages from the point of view of the outcome of therapy, patient satisfaction and compliance. The former approach makes full use of the professional's expertise, provides concrete information on problems and focuses on the patient's problem, which usually takes a short period of time. The latter approach is a patient-centred method where the patients are encouraged to express their own thoughts and feelings freely and, on the other hand, define and resolve problems. Patients are thus involved in the treatment and decision-making processes, and therefore can recognise that they are able to change their own lives. The major criticism raised against the non-directive interview lies in the fact that it requires a large amount of time, which is a rare phenomenon in healthcare. Nevertheless, non-directive 
interviews provide careful listening, confirmation of patients' thoughts and feelings, empathy and possibility of selfdisclosure, which form the base of effective interviewing.

Another important issue in achieving efficacy in healthcare interviews is the use of phases in the interview process. According to Byrne and Long (1976), the healthcare or medical interview consists of six main phases: initiation, exploration, examination, diagnosis, discussion of further treatment and termination. The initiation phase includes establishing a therapeutic climate, clarifying the purpose of the meeting and formulating a contract between the professional and the patient. In the exploration phase the doctor identifies problems, manages feelings and develops the cooperating skills of the patient. The doctor then conducts a physical examination and diagnoses the problem. The doctor and patient detail further treatment. The termination phase is no less important than any of the former ones, because professionals summarise and repeat issues and discuss plans for future follow-up, which are necessary for the therapeutic process. Several communicative errors may occur if any of the above factors are omitted from the three phases.

\section{Interview phases in a therapeutic interview}

According to Stuart and Sundeen (1995), therapeutic medical interviews consist of only four phases: (1) The preparation phase involves planning for the first meeting with the client; (2) in the initiation phase the professional clarifies the purpose of the meeting; (3) the exploration phase is often called the working phase during which the clinician analyses and works on the client's problems; (4) the termination is characterised by summarising issues and expressing feelings about termination.

Todd's taxonomy on speech acts (1983) in a clinical context provides a comprehensive view on doctor-patient communication. According to this classification, speech acts comprise statements, questions, answers, directives and reactives. As the therapeutic interview involves questions, answers, directives and reactives to the greatest degree, the linguistic peculiarities of these speech acts can be examined. The excerpts of the analysis come from a kidney transplant patient at the Medical University of South Carolina. The excerpt involves 1
456 words $(n=6779)$ i.e. 4 pages. The transcript is also available on MUSC Health Video Podcasts*. A 41-year-old patient has received a kidney from his brother after years of dealing with proteinuria, end stage renal disease and dialysis. In this interview the patient describes his experience undergoing dialysis, the kidney transplant procedure and recovery. He also explains why transplant patients take immunosuppressant drugs.

The corpus to be analysed has its weak and strong points. Despite its relative briefness, this single interview offers an insight into a discourse genre (therapeutic doctor-patient consultation) whose accessibility is rather difficult for the lay public. MUSC Health Video Podcasts provide both transcript and MP3/video playback facilities. In this way, not only the paralinguistic but also the nonverbal linguistic features of communication can be observed. This factor may provide an advantage for researchers in being able to study linguistic corpora in a holistic way. As compared to the MUSC Health Video Podcasts, the British National Corpus offers samples of only general practice consultations without video access (Cerny, 2011).

The purpose of the analysis is to examine speech acts in the different phases of the interview. The preparation phase is not included in the excerpt.

\section{Initiation}

This phase aims to foster trust and understanding towards the patient by creating a non-threatening climate for the professional-patient relationship. The doctor uses a directive to make the patient speak about his problem, reduce his anxiety about the new situation, and clarify the purpose of the interview. Using a directive shows the doctor's interest towards the patient and gives the patient the freedom to express their own thoughts and feelings.

(1)

Doctor: Don Holzheimer has a very special story to tell. He has received a kidney transplant. And, Don, let's have you tell your story, really, thinking about that person out there who will be listening to this because they, or someone they love, will getting a kidney transplant. First of all, how old were you when you were told you were going to need a transplant?

Patient: I was 41. 
Patient: That's absolutely true. In 1992, I was diagnosed with chronic renal failure, which means that my kidneys were slowly deteriorating. They, actually, didn't know the cause. I had biopsies, and different tests, done to pinpoint the cause of my kidney failure, and they're not really sure. I think one of the things that may have contributed is that I had undiagnosed high blood pressure for such a long period of time, which actually started doing some serious damage to my kidneys.

\section{Exploration}

Exploration is the working phase of the interview, during which the clinician works on the client's problems. The major task of the professional is to help the patient reveal personal problems. The doctor's question is an open one, letting the respondent speak freely. Therefore, the answer displays the characteristic features of self-disclosure.

(2)

Doctor: Now, at that time, you went on dialysis? Is that right?

Patient: I did. That's correct.

Doctor: What is dialysis like?

Patient: Oh, boy. Well, dialysis, at the beginning, is actually not too terribly bad. To receive dialysis, a catheter is inserted, with a of couple tubes hanging off your chest. That's how they hook you up to the machine in the initial stages of dialysis. It's not the best means for dialysis, because there's a lot of opportunity for infection. It's difficult to keep the tubing clean.

Later on, after you've started dialysis, you undergo fistula surgery. Essentially, what happens with the fistula is that they connect an artery and a vein in your forearm or upper arm. Then, the amount of blood that begins to circulate through the vessel strengthens it. If you just use a regular vein, it would eventually collapse, because the wall isn't strong enough to get stuck [with a needle] many times. With dialysis, you basically go three times a week, with an average of four hours per treatment. With the fistula, they build up that vein and it can eventually handle the rigors of dialysis.

\section{Termination}

Termination is an essential phase in therapeutic interviews. The clinician not only summarises issues but assists the patient in expressing their feelings. Within a 'small talk' the clinician asks closed questions about personal matters relating to the patient. The aim of this section is not gathering information but talking about issues that may be important to the patient. In this way, the patient can express feelings about his condition. The length of the turns are shorter in this phase compared to the previous one, as the participants' intention is not elaborating but summarising and expressing their thoughts and feelings.

(3)

Doctor: And, your general health; energy, everything, is okay?

Patient: Oh, yes. It's phenomenal, actually.

Doctor: What do you work as, Don?

Patient: I'm a pharmacy tech here, at MUSC, in the adult inpatient pharmacy.

Doctor: Oh, that's fantastic. And, do you have family?

Patient: My family lives in Ohio.

Doctor: I see.

Patient: I moved down here in 2008 to attend school. And, after school, I was able to land a job here, at MUSC.

Doctor: Well, we're lucky to have you in our community. Thanks so much for sharing your story.

Patient: Thank you.

Questions and directives used by the doctor have the sole purpose of making the patient express their feelings in the situation.

Therapeutic interviews can be divided into two groups: directive and non-directive. These different approaches to interviewing involve different linguistic peculiarities in the interaction between doctors and patients. The sequential organisation of the nondirective, therapeutic interview demonstrates the peculiar attitudes and language use of the speakers. The analysed interview shows the characteristics of the patient-centred questioning techniques of the clinician, who provides an opportunity for the client to speak freely.

\section{The sequential organisation of a therapeutic dialogue}

Mishler (1984) divided professional-patient interactions based on 25 interviews into two groups. The traditional interactions called "unremarkable interviews" emphasise the control function of the physician. The professional aims to gather information and 
diagnose the disease. The interview starts with the physician's question followed by the patient's response. The physician assesses the respondent's answer, following with a new question or clarification. The elaboration of the patient's answer closes the sequence. In this sequence type, there is no possibility for the patient to initiate topics or contradict the doctor. Although the interview below can be considered as a therapeutic one with a non-directive questioning technique, it displays the characteristics of exploration (directive questioning), as well as emphasising the dominant role of the professional.

(4)

Doctor: And, do you have a family?

Patient: My family lives in Ohio.

Doctor: I see.

Any other difference from this sequence of talk may result in the fragmentation of the conversation. Mishler (1984, p.192) considers the unremarkable interview as less humane and effective as compared to another doctor-patient interaction called the "problem interview."

Problems of the patient are associated with the therapeutic part of the interview, when talk on treatment may lead to behaviour change in the patient. In "problem interviews" the patient tries to emphasise his or her own values, worldview or personality or uttering the "voice of the lifeworld" as Mishler formulated it. The perspective of the patient as surplus content may occur in the sequences of the doctor-patient talk. This attitude of the patient may enhance sequences, thus the professional can get to the conclusion of the talk by establishing greater discourse units. This kind of discourse displays a less directed but more fragmented character than the "unremarkable interview" type. The present interview phase displays the features of fragmentation as well.

(5)

Doctor: Incredible gift. What was the surgery like for you? Was it difficult?

Patient: Actually, the day of surgery, I was really at peace. I didn't, really, have too many worries. I think the biggest thing I joked about was that they might drop it on the floor, have to clean it off, and put then put it in me. But, basically, the day of surgery, I was pretty much at peace.
It was just amazing, the day of surgery. The donor goes first. So, my brother went into surgery first. It was just unbelievable. I was in there for several hours; six to eight hours, but it seemed like two or three minutes. I remember when I laid down on the table, it was freezing cold. Then, when they put the warm blanket on me, I spoke to the nurse for about two minutes. And, the next thing I remembered, I had woken up in intensive care, and it was already done.

This paper intends to explore more linguistic features of a non-directive, therapeutic interview; therefore, further health communication variables need to be introduced for analysis.

\section{Empathy}

The definition of what the famous therapist Carl Rogers (1995) calls empathy seems to give insight into this idea. The idea of empathy offered by him is a psychological process that involves entering into another person's world without prejudice and accepting him or her as fully as possible. Applying empathy and empathic skills plays an essential role in the cooperation between clients and experts. On the one hand, Buda (2006) claims empathy is the ability to understand another individual; on the other, it is also a means of establishing a connection between clients and professionals. Tringer (2007) states that empathic behaviour features not only a reflecting but also verbalising perspective. Verbalising shows the active efforts of the therapist to express the cognitive and affective entities understood in patients. The success of the interaction depends on verbalisation or communication to a great extent. The main difference between empathic and explorative communications lies in the mode of interviewing. While the latter communication is manifested in questioning, the former one rarely uses direct information gathering. Paraphrasing, repetition, interpretation, confirmation are all those psychological-communicative techniques which may contribute to effective therapeutic behaviour towards patients. According to Tringer (2007), empathic communication technique may contribute to a better understanding of the patient and to establishing a trustworthy atmosphere in which he or she can communicate freely. Rogers (1995) emphasises that a therapist 
should express empathy, positive regard and congruence (genuineness) toward a patient to improve his or her state. These factors, known as therapeutic conditions, must cause openness in patients who, on the one hand, can communicate more freely, and on the other hand such a supportive atmosphere may contribute to resolving conflict and, to some degree, the recovery of the patient.

The theoretical framework of comforting strategies derives from constructivism, an approach based on the idea that the structure of behaviour reflects the structure of thought. Comforting messages are characterised as interpersonal constructs through which participants evaluate, interpret and emotionally influence the thoughts and behaviour of each other.

\subsection{Confirmation}

Confirmation refers to the verbalisation aspect of the therapist's empathic attitude to affect and alter the self-image of the client in a positive way (Tringer, 2007). Although confirmation seems to be an essential communication variable from the client's perspective, in healthcare settings a limited amount of research deals with the issue. Among them, Grant and Rosenfeld (2000) argue that confirmation can be associated with satisfactory interaction between professionals and clients, and consequently that confirmation is important in the selfassurance of patients. Satisfactory interaction emphasises the positive side of communication, which may represent supportive behaviour to patients. Supportive behaviour provides emotional help for people in need, including listening and showing concern. The latter two aspects are revealed in supportive messages that can offer encouragement, acceptance and reassurance for people. Emotional support cannot be divided from informational support, which may enable patients to reexamine their courses of action.

Confirming and disconfirming responses were initiated by Sieburg (in: Northouse, 1998). The former part includes acknowledgement, agreement, supportive responses, clarification and positive feelings. On the other hand, the latter part contains irrelevance, impersonal and incoherent responses, or interruption. While confirming responses reduce the feelings of separation, fear, and abandonment, disconfirming responses make persons value themselves as an object.
Taking the systems perspective into consideration, confirmation seems to function as a feedback mechanism in the interaction of professional and client. After the findings of Garvin and Kennedy (1986) it can be stated that confirming and disconfirming responses are reciprocal in the communicative process (Northouse, 1998). Health professionals who feel confirmed possess the emotional strength to then project it towards clients, whom they treat as unique human beings. As a result, clients are more likely to express their feelings freely and show self-disclosure towards their therapists. In order to strengthen client health the professional confirms his or her answers by supporting messages. The chain of reactions can continue until the client confirms to the professional the success of the emotional and informational transfer.

From the point of view of pragmatics, confirming responses may take the form of assessments as speech acts in doctor-patient dialogues.

\section{Structure and functions of speech acts in the therapeutic interview}

Elaborating on the features of doctor-patient dialogues further on, Coulthard (1977) and Mishler (1984) emphasise the three-part structure in institutional conversation. On the one hand, Mishler considers this structure in the form of question, answer, assessment; Todd (1983, p.165) views the sequence as question, answer and reactive. In therapeutic interviews, both sequential sets play an important role in discourse. According to Denning (2004) assessments are evaluations, judgments, or opinions about the world. In clinical settings assessments are developed via confirmative feedbacks, such as acknowledgement, supportive responses, clarification and positive feelings that show empathy towards the patient. Backchannel responses fall into three categories: non-lexical, phrasal, and substantive reactives (Young and Lee, 2004). Functionally, reactives can be assessments as well, but they are primarily phatic expressions, serving meta-communicational purposes in conversation. Reactives as nonlexical backchannels are used to demonstrate the listener's attention (Cerny, 2009). This analysis intends to demonstrate that assessments are between answers and reactives as speech acts. While answers give a substantive response to a question, assessments provide positive emotional reflection to the respondent's utterance. 
Reactives following answers only demonstrate the listener's attention. The examples below demonstrate the two different feedback types of the speech partners and focus on the uses of speech acts and the length of turns in the conversation excerpts.

Assessment as acknowledgement is the way the listener responds directly to what the other person communicated. The listener shows her understanding towards the speaker owing to the troubles in his life.

(6)

Patient: I moved down here in 2008 to attend school. And, after school, I was able to land a job here, at MUSC.

Doctor: Well, we're lucky to have you in our community. Thanks so much for sharing your story. (acknowledgement)

Assessment can take the form of supportive response when the listener supports what the other person is talking about.

(7)

Doctor: What do you work as, Don?

Patient: I'm a pharmacy tech here, at MUSC, in the adult inpatient pharmacy.

Doctor: Oh, that's fantastic. (supportive response)

Assessment can appear as a clarification when the listener attempts to make the content of the speaker's message more understandable. It may include paraphrasing the speaker's message. The purpose of using clarifications as confirming responses is to reinforce what the patient is saying. It may involve asking the client to express in detail how he or she feels.

In order to clarify the patient's feelings, emphasis is placed on the description, not on the explanation of emotions. At the same time, as an assessment clarification means direct acknowledgement of the patient and encouragement to express what he or she feels.

(8)

Doctor: And, as I understand it, you had been suffering, to some degree, for many years with low-level kidney problems that became quite severe in the last few months before your transplant. (clarification)

Patient: That's absolutely true. In 1992, I was diagnosed with chronic renal failure, which means that my kidneys were slowly deteriorating. They, actually, didn't know the cause. I had biopsies, and different tests, done to pinpoint the cause of $m y$ kidney failure, and they're not really sure. I think one of the things that may have contributed is that I had undiagnosed high blood pressure for such a long period of time, which actually started doing some serious damage to my kidneys.

So, I started seeing a nephrologist in 1992. And, for the most part, my lab levels, they were generally on the high side. But they were on the maintained high side. So, there was a lot of fluctuation in my lab results. However, in 2006, that's when the ball really dropped. And, at that point, I was only seeing my doctors semi-annually, because everything was maintained so well. At the end of 2006, I went to see my doctor for my regular appointment. They did a blood draw, and my creatinine level was about ten times the norm. So, that was a clear indication that something was seriously wrong with my kidneys.

The listener can express his or her positive feelings responding to another person with affirming uncritical feelings.

(9)

Doctor: Now, how about your kidney transplant procedure? I know you got a kidney from your brother.

Patient: That's correct.

Doctor: Incredible gift. (positive feelings)

Non-lexical backchannel (reactive) is a vocalised sound that has little meaning, but expresses the attention of the listener. The doctor's reactive expresses her empathy with the patient.

(10)

Doctor: And, how about the recovery period? Was that difficult, or did it go smoothly?

Patient: It wasn't too bad. I can remember my second day in the hospital. My doctor said: Well, we don't want you just sitting around in here. We want you to get up and start moving around. The very first day, the toughest thing was trying to sit up. When you have a kidney transplant, they don't remove the nonfunctioning kidneys unless they're cancerous, or there's some other risk if 
left in. So, basically, I have three kidneys right now; two that don't work, and one that works.

So, the toughest part is, they have to cut through the muscles in your abdomen, in order to implant the donated kidney. It's actually placed frontally, instead of in the back. So, sitting up, oh, it was excruciatingly painful. It was really tough to sit up. But, once I got up, I was able to stand up. Then, it was just fine. But, the very first day that I did try to walk, I walked, maybe, a distance of six to eight feet. I thought, okay, that's enough.

Doctor: Wow. (reactive as assessment)

Coming from the characteristic features of therapeutic interviews, both parties may initiate reactives as Todd (1983) and Cerny (2009) claim. However, the function between the reactives of the speech parties is different. Coming from the previous example, the doctor's reactive shows empathy; here, the patient's reactive serves a different function. It expresses that the speaker's message is approved. The form of the latter reactive is phrasal.

(11)

Doctor: Clearly, you've gotten back. It must have been very exciting when starting peeing like a normal person again.

Patient: That's true. That's very true. (reactive)

Doctor: Now, you mentioned, I think, earlier, that you're on a lot of immunosuppressant drugs.

Patient: That's correct.(reactive)

\section{Conclusion}

The present analysis has its limitations, which mainly include the fact that there is only one text in the corpora and that the paper focuses on a singular text genre (therapeutic interview).

Despite these limitations, the outcomes of the study seem to suggest that the threephased structure, sequential organisation and functions of the speech acts in a therapeutic interview can be considered a universal phenomenon in the field of medicine (Byrne and Long, 1977; Mishler, 1984; Northouse, 1998; Cerny, 2009).

The analysis concerning the phases of the interview reveals that the purpose of the expert is to reduce the patient's anxiety, assist the patient in expressing feelings freely, discuss issues related to the illness, and provide support in each phase. This purpose is realised by the use of the speech acts in the dialogues. The use of open questions and a directive by the doctor makes the patient reveal problems and express their feelings in connection with the illness. In the termination phase, closed questions are not only used for information gathering or limiting the patient's control over their thoughts, but for showing empathy by the professional as well.

The sequential organisation demonstrates the characteristic features of the "problem interview." Here, the patient's sequences are longer than the doctor's ones, displaying the characteristics of patient-centred communication. The purpose of this interview type is to present the patient's own thoughts and feelings. In this way, the patient-centred method of interviewing has been achieved by establishing greater discourse units.

To sum up, doctor-patient dialogues have a three-part speech-act structure: question, answer, assessment. On the grounds of the results it can be concluded that assessments have two types in medical interaction: confirmative responses and reactives. Assessments as confirmative responses have several functions, such as providing acknowledgement, support, clarification and positive feelings. Reactives as vocalised sounds may show the attention of the listener. In the case of a doctor, reactives demonstrate empathy towards the patient, but the patient's use of reactives expresses only attention.

\section{References}

BUDA, B., 2006. Az empátia. Budapest: Urbis Kiadó.

BYRNE, P.S. and LONG, B.E., 1976. Doctors talking to patients. London: H. M. Stationery Office.

CERNY, M., 2009. The three-part structures of medical interviews. Discourse and Interaction, vol. 2, no.1, pp. 135-147. 
CERNY, M., 2011. Doctor-patient communication research in a digital world. Topics in Linguistics, vol.7, pp. 49-54.

COULTHARD, M., 1977. An introduction to discourse analysis. Longman: London.

FISHER, S. and TODD, A., 1983. The social organization of doctor-patient communication.

Washington, D. C.: Center for Applied Linguistics. John Benjamins Publishing Company.

FOUCAULT, M., 1969. The archeology of knowledge. Trans. A. M. Sheridan Smith. Routledge: London. FOUCAULT, M., 1994. The birth of the clinic. New York: Tavistock.

GARVIN, B.J. and KENNEDY, C. W., 1986. Confirmation-disconfirmation: A framework for the study of interpersonal relationships. In: P. Chinn, ed. Nursing research methodology. Rockville, MD: Aspen GRANT, C. H. and ROSENFELD, L. B., 2000. Patients' perception of physician communication and outcomes. Health Communication, vol. 12, no. 1, pp. 23-39.

LABOV, W. and FANSHEL, D., 1977. Therapeutic discourse: Psychotherapy as conversation. New York: Academic Press.

MCQUOWN, N. A., 1971. Forward. In: N. A. McQuown, ed. The natural history of an interview.

Chicago: University of Chicago, pp. 1-5.

MISHLER, E. G., 1984. The discourse of medicine. dialectics of medical interviews. Norwood: Ablex

Publishing Corporation.

MOSOVICI, S., 2000. Social representation: Studies in social psychology. London: Polity Press.

NORTHOUSE, P.G. and NORTHOUSE, L. L., 1998. Health communication. Prentice Hall: Connecticut.

PARSONS, T., 1991. The social system. London: Routledge.

PERCY, W., 1987. The message in the bottle: How queer man is, how queer language is, and what one has to do with the other. New York: Farrar, Strauss, and Giroux.

ROGERS, C., A way of being. 1995. Boston: Houghton Mifflin.

SACKS, H., SCHEGLOFF, E. and JEFFERSON, G., 1974. A simplest systematics for the organization of turn-taking for conversation. Language, vol. 50, pp. 696-735.

SCHIFFRIN, D., TANNEN, D. and HAMILTON, E. E., 2008. The handbook of discourse analysis. Blackwell Publishing.

SHUY, R., 1983. Three types of effective exchange of information in the medical interview. In: S.

Fisher and A. Todd, eds. The social organization of doctor-patient communication. Washington, D. C. Center for Applied Linguistics, pp. 89-202.

SIEBURG, E., 1969. Dysfunctional communication and interpersonal responsiveness in small groups. Doctoral dissertation, Denver, 1969. University Microfilm. No. 69-21. p. 156.

STUART, G. W. and SUNDEEN, S. J., 1995. Principles and practice of psychiatric nursing. St. Louis: C. V. Mosby. In: L.G. Northouse, ed. Health Communication. Prentice Hall. p. 62.

THORNBORROW, J., 2002. Power talk: Language and interaction in institutional discourse. London: Longman.

TRINGER, L., 2007. A gyógyító beszélgetés. Budapest: Medicina Könyvkiadó.

WAITZKIN, H., 1989. A critical theory of medical discourse:Ideology, social control, and the processing of social contexts in medical encounters. Journal of Health and Social Behavior, vol. 30, pp. 220-239.

WODAK, R. and MEYER, M., 2009. Methods for critical discourse analysis. London: Sage.

YOUNG, R. F. and LEE, J., 2004. Identifying units in interaction: Reactive tokens in Korean and English conversations. Journal of Sociolinguistics, vol. 8, no. 3, pp. 380-407.

Internet sources:

DENNING, P.J., 2004. Assertions and assessments.

Available at:

http://www /denninginstitute.com/pjd/TT/Assert/Assess pdf.

HAVE, P.ten, 2002. Sequential structures and categorical implications in doctor-patient interaction. Available at:

http://www./pscw. uva. nl/emca/seqstruct. htm

AUSTIN, L., 2014. Kidney transplant: Interview with a kidney transplant patient. * MUSC (Medical University of South Carolina) 
Available at:

http://www. /muschealthcom. multimedia/Podcasts/transcription.aspx?podid

http://www./muschealth.com/multimedia/Podcsts/displayPod.aspx?podid=843

Author's address and contact details

Monika Gyuró, assistant professor

Faculty of Health Sciences

Pécs University

Mária u. 5-7, 7621-Pécs

Hungary

Phone: +36 72251146

E-mail: gyuro@etk.pte.hu 